\title{
Calculated and experimental determination of erosion zones in the flow part of the vane type pump
}

\author{
Dmitry Svoboda ${ }^{1}$, Evgenii Ivanov $^{1}$, Aleksandr Zharkovskii ${ }^{1}$, and Igor Borshchev ${ }^{1, *}$ \\ ${ }^{1}$ Peter the Great St. Petersburg Polytechnic University, Polytechnicheskaya, 29, St. Petersburg, 195251, Russia
}

\begin{abstract}
The results of numerical and experimental investigations aimed at creating a methodology for predicting the erosion characteristics of vane pumps were conducted in this paper. This methodology especially relevant in the case of pumping liquids with physical properties different from water. The methods of computational fluid dynamics (CFD) well predict the operation failure due to cavitation and allow us to determine the areas of possible cavitation erosion. The conditions for the absence of cavitation erosion also could be predicted with the help of CFD methods. In order to verify the numerical prediction of cavitation erosion, test bench working on water was created, which allows to verify methods of experimental investigations of cavitation erosion with the help of express analysis based on paint coatings.
\end{abstract}

\section{Numerical calculation of the cavitation characteristics}

Numerical studies of the cavitation characteristics of a vane type pump using computational fluid dynamics methods are necessary for determining the quality of a designed flow part $[1,2,3]$. There are surface and detachable forms of cavitation possible in vane type pumps, which lead both to a deterioration of energy characteristics and to cavitation erosion of the pump flow part elements, primarily the impeller. Problems of cavitation erosion are compounded in the case of pumping aggressive, multifractional, polluted, oil and other liquids, the physical properties of which are different from water and the intensity of micro-blows arising from the "collapse" of cavitation bubbles can increase dramatically. In this regard, there are questions about how to improve the flow part of the pump, to prevent damage from cavitation. In many cases, bench tests on the actual fluid are impossible, or there are some difficulties that significantly increase the cost, complexity and the time for obtaining experimental characteristics.

Cavitational failure of the vane pump operation is predicted well with the help of numerical methods incorporated in computational software packages, such as ANSYS CFX (Fig. 1).

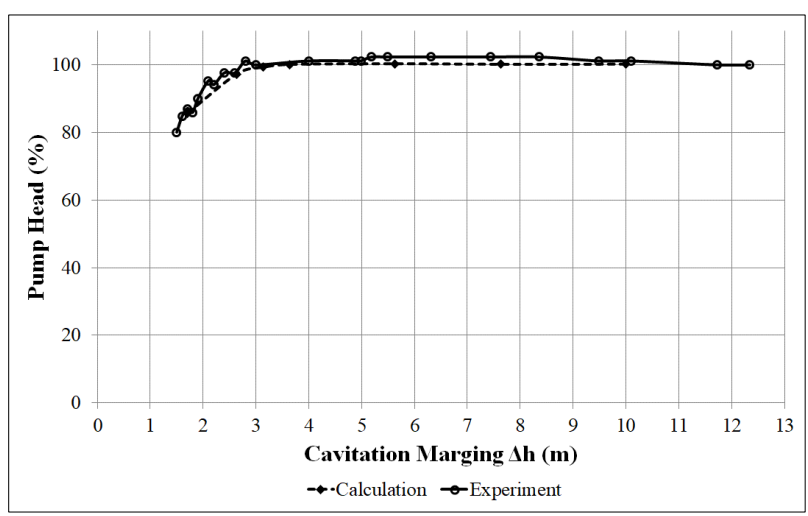

Fig. 1. Cavitation characteristic of an axial pump $(\mathrm{KQ}=0.41$; $\mathrm{KH}=0.15)$.

Presented in Fig. 1 numerical studies of the axial pump cavitation characteristics were carried out in the Ansys CFX software package using a two-phase flow model water-air (steam). In CFD calculations, cavitation is considered as a change of state from liquid to vapor when the pressure in the flow part of the pump drops to the value of the saturated steam. At the entrance to the computational domain was set the total energy of the fluid, at the exit - the flow rate corresponding to the mode for which experimental data was available. The value of the vapor pressure for the temperature $\mathrm{t}=25^{\circ} \mathrm{C}$ was $\mathrm{p}_{\mathrm{n}}=3574 \mathrm{~Pa}$. In accordance with ISO 9906:1999, the value of the net positive suction head (NPSH3) was determined by a $3 \%$ drop in the head magnitude. The cavitation characteristics obtained from the numerical calculation of a flow with a two-phase cavitation model are in a good agreement with experimental data. Numerical investigation allows to determ the moment of

\footnotetext{
* Corresponding author: borshchevspbspu@mail.ru
} 
the axial pump's operation failure parameters and find the value of the NPSH.

\section{Experimental and investigation of axial pump}

numerical

There are no methods for predicting the erosion characteristics of pumps at present time. Work in this direction is carried out in the laboratory of hydraulic machinery construction, SPbPU [4]. An axial-type pump for pumping a heat-transfer liquid metal lead was designed using hydrodynamic modelling [5]. Then, pump was investigated numerically and experimentally. Operating fluids were water and actual fluid - liquid metal lead.

Lead as a heat carrier has a significantly different physical properties from water. Therefore, cavitation failure during the model tests does not occur. However, cavitation erosion was detected. The damaged areas had a wavy-porous look, and the maximum depth of the cavities reached $1 \div 1.5 \mathrm{~mm}$. Such ulcerations were observed in the peripheral part of the blades and in the region of their connection with the rim (Fig. 2).

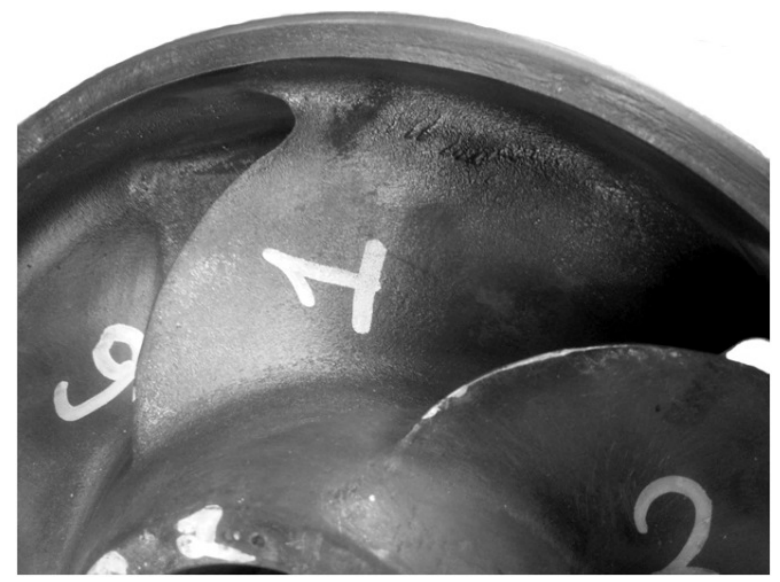

Fig. 2. The impeller of the axial pump after durability tests-

The number of tests were not numerous and were fragmentary, so it was impossible to investigate the process of the uprising and development of cavitation erosion on their basis. For a more detailed study of this process and the creation of methods for numerical prediction of cavitation erosion, it was decided to create a test bench and conduct detailed studies with it. There is some information in the literature that the flow parts designed for liquid metal coolants and tested on water, had high cavitation properties when working on heavy liquid metal coolants [6].

For these purposes, a water test bench was created in the laboratory of hydraulic machinery construction, SPbPU. This bench allows to conduct experimental studies of axial pumps for cavitation erosion [7]. At the first stage, on the base of the digital model of the stand (Fig. 3), using the ANSYS CFX hydrodynamic package, numerical studies of the cavitation development phenomena in the pump flow part were performed. The next step is to perform experimental studies on the same modes, as in numerical investigation and compare them.

Conducted calculations showed, that the vapor regions have appeared approximately in the same places, where erosion cavities appeared during the experiment on liquid metal lead with net positive suction head $\Delta \mathrm{h}=1.4 \Delta \mathrm{h}_{\text {critical }}$. For the complete absence of cavities, it is necessary to provide $\Delta \mathrm{h}=2.5 \Delta \mathrm{h}_{\text {critical }}$ (Fig. 4).

For experimental studies of cavitation erosion on the water test bench placed in SPbPU using express methods of analysis based on paint coatings while ensuring the similarity of the NPSHA, a program of such tests has been developed. Comparison and analysis of the vapor areas with cavitational destructed zones allows to conclude that it is possible to work out the flow part of the pumps using modern 3D-methods and CFD. Such analysis permits to make further recommendations on the value of the allowed NPSH to ensure the non-erosive operation of the pump on the actual working fluid by research on the water.

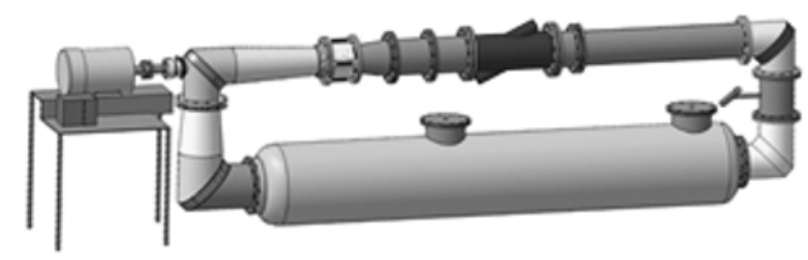

Fig. 3. Test bench working on water for model tests of axialflow pumps. 


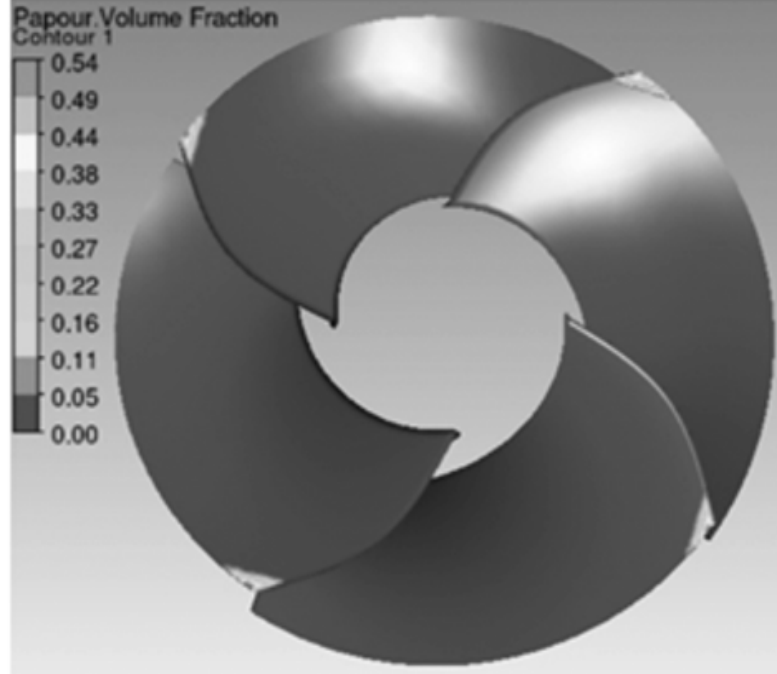

a)

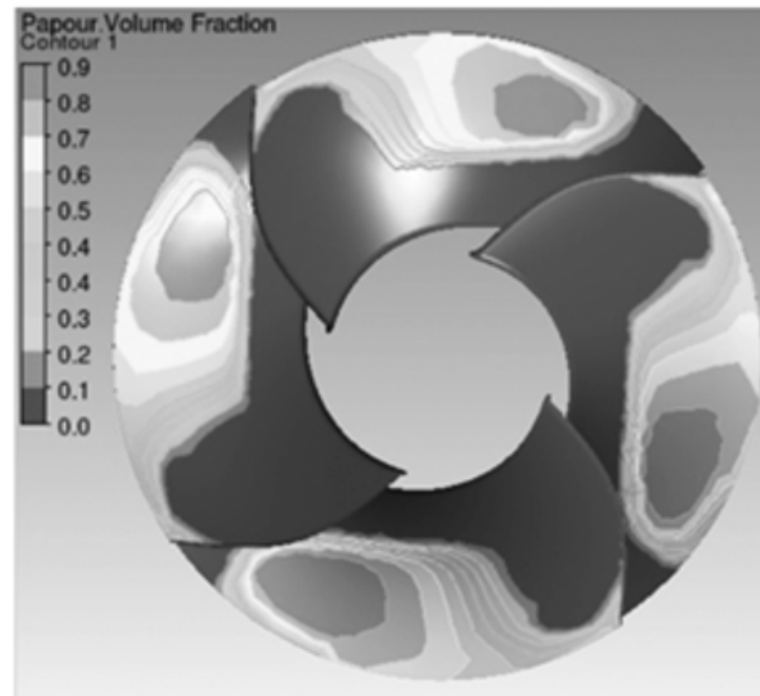

c)

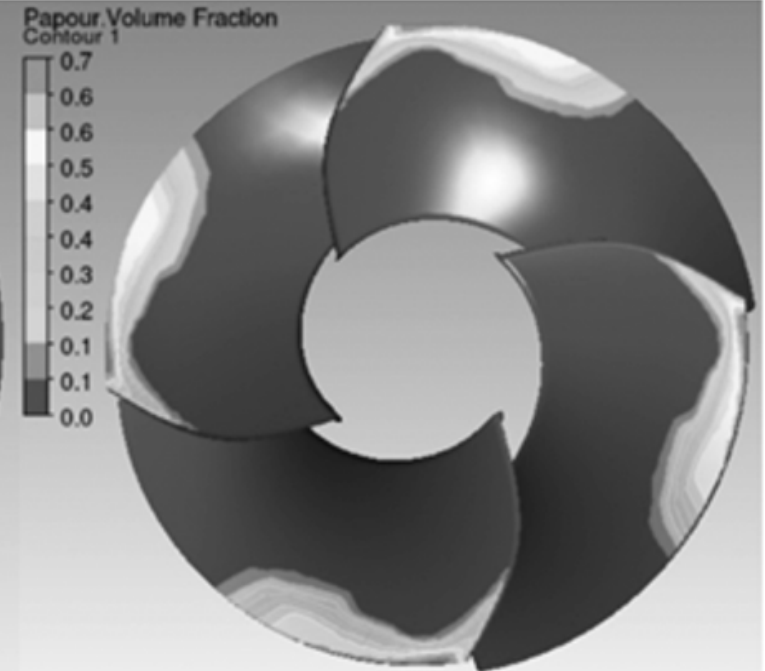

b)

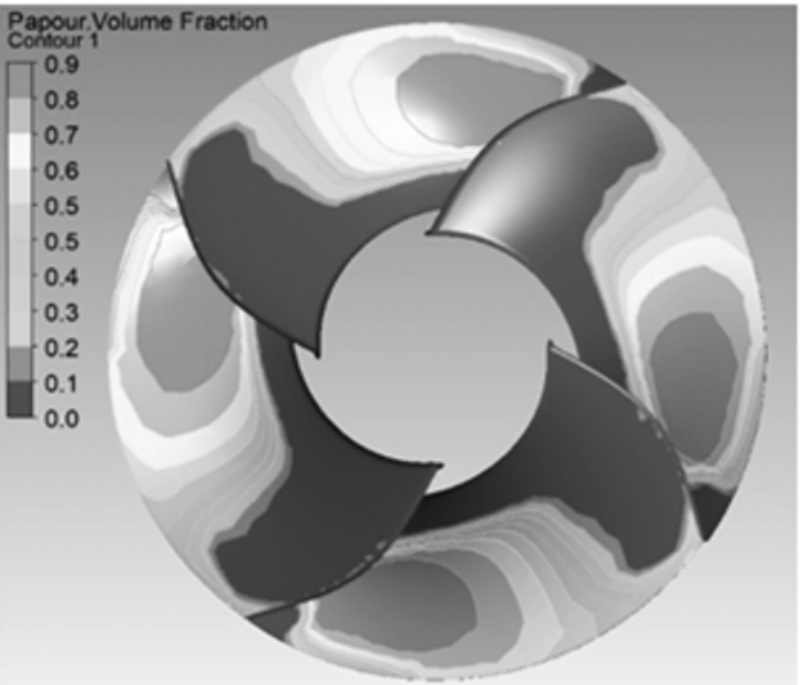

d)

Fig. 4. Areas with vapor cavities on the back side of the impeller blade $(\mathrm{n}=1500 \mathrm{rpm})$ with different values of NPSH: a) $\Delta \mathrm{h}=3.7 \mathrm{~m}$; b) $\Delta \mathrm{h}=1.7 \mathrm{~m}$; c) $\Delta \mathrm{h}=1.2 \mathrm{~m}$; d) $\Delta \mathrm{h}=1.18 \mathrm{~m}$.

\section{Conclusions}

1. The methodology of calculated estimation of cavitation erosion in a vane pump was proposed.

2. The developed methodology will be specified after its experimental testing on a specially created stand for accelerated research of cavitation erosion using easily destructible lacquer coatings.

3. The methodology can be used to evaluate the cavitation erosion in any structures where cavitation is possible and for any working fluids (water, oil, cryogenic liquids, etc.).

\section{References}

1. V. Volin, E. Lunaci Trudy VNIIGidromasha 37, 122$131(1968)$
2. E. Lunaci, D. Vojtashevskij Trudy VNIIGidromasha 42, 219-238 (1971)

3. E. Lunaci Inzhenernyj vestnik 8, 53-65 (2015)

4. D. Svoboda, A. Zharkovskiy, E. Ivanov Izvestiya Samarskogo nauchnogo centra rossijskoj akademii nauk 18, 287-291 (2016)

5. D. Svoboda, A. Zharkovskiy, P. Dyagilev Innovative designs and technologies of nuclear power III, 218223 (2014)

6. . Babin, F. Mitenkov, E. Novinskiy, Tez dokl mezhdunarodnoj konferencii po kavitacii v nasosah s natrievym teplonositelem (1985)

7. D. Gorbatov, D. Svoboda, XLVII Week of science SpbPU, 98-100 (2018) 